\title{
Educational Computer Games and Spanish Content Learning
}

\author{
Timothy Dedeaux \\ Taralynn Hartsell \\ The University of Southern Mississippi
}

\begin{abstract}
The purpose of this mixed-methods study was to determine differences in engagement, satisfaction, and Spanish language content learning among participants playing one of two different educational computer games. Additionally, this study served as preliminary research for future research projects to detect and correct problems at the pilot stage. Participants were briefly introduced to the Spanish content material prior to using the computer games and completed pretests, post-tests, and satisfaction/engagement surveys as a way to obtain learning results. The small sample size acquired for the study did not yield any statistically significant difference, but the research did permit examination of the procedures used and a report of results in a more descriptive manner. The findings led to possible ideas for future research and the necessity to revise the pre- and post-tests.
\end{abstract}

Keywords: computer games, computer-based learning, foreign language, learning interactivity, drill and skills

\section{Introduction}

Computer games in education will not disappear anytime soon because of their value in assisting learners to acquire and practice knowledge and skills. Games have become a permanent part of the cultural landscape, and in particular to the digital age. Though computer games are long thought to be a hobby of teenage boys, the reality is that gamers' average in age of 34 years and $40 \%$ of these gamers are women (Entertainment Software Association, 2010). The question of whether computer games are a good or bad influence has been rendered largely moot by their near-ubiquity. Young children, adolescents, young adults, and even senior citizens play video games in increasing numbers that range from dedicated console games to casual
Flash and Facebook games played on personal computers, to gaming apps of many sorts played on mobile computers such as the iPad, Android, and even Kindle (Entertainment Software Association, 2010).

Though there have been a number of research studies that determined the effectiveness of videogame-based learning relative to traditional instruction, little research has been performed comparing different types or categories of educational computer games and their effectiveness in teaching and learning. In another word, studies that investigate whether one type of computer-based game such as simulations may be more efficient to learning a subject matter than other type has rarely been done. 
This study will examine differences in engagement, satisfaction, and Spanish language content learning among adult participants playing one of two educational video games. The participants will not be fluent or conversational in Spanish, but have been exposed to Spanish through general cultural interchange, popular media, and even high school Spanish classes. The two types of computer games examined were both within the category of drilland-skill type of games, but the format of both games were different, a variable investigated in this study. This paper summarizes the context of this mixed-methods research study that describes the results based upon participants' interactions, motivation levels, and changes in knowledge and attitudes toward using computer games to learn Spanish.

\section{Literature Review}

Though much research has been done in recent years comparing educational computer games to traditional teaching methods, relatively little has been done comparing different types of educational computer games, aside from Kebrichti and Hirumi's (2008) exploration of pedagogical foundations of many then, current educational video games. The researchers believe that among different computer games available, greater engagement can lead to greater achievement. In addition, the researchers assume that more similar the educational computer games are to successful commercial video games, the more engaging and effective the game will be for the user.

Computer games have long been a topic of interested for educators, having had their origins as military training tools before moving first into business training and only then into entertainment, where they took hold both economically and perceptually (Abrams, 2009). While the current generation of students is known to play video games regularly, and in fact, spend a great deal of their time fully engaged in multimedia (Prensky, 2005), their acceptance of the educational uses of videogames should not be taken for granted. Bourgonjon, Valcke, Soetaert, and Schellens (2009), in a study of 858 secondary school students, found that ease of use and perceived usefulness of the specific games were powerful predictors of students' acceptance of educational video game use, and more powerful than gender or experience in playing video games. For this particular research study, ease of use and perceived usefulness were assumed by the researchers to affect the participants' acceptance of the two computer games used.

All computer games are not created equal, either in entertainment value or in educational pedagogy. The greatest point of concern is not the inappropriate material sometimes present in commercial off-the-shelf video games, but the "Shavian reversals" (Papert, 1998, ๆ2) wherein educational video games are neither entertaining nor pedagogically sound. Maximizing both engagement and educational content is of great importance when creating or selecting educational video games, and goes to the heart of the comparison undertaken in this study.

There has been a great deal of research performed on what makes computer games, whether educational or not, effective and engaging. Papert (1998) noted that in order to be engaging, games should not be easy. Noneducational games are never marketed as easy. They are in fact very difficult to play that also makes them engaging. Educational computer games should be difficult and complex in the same ways as commercial games, and should be focused not on content such as knowledge or rote skills like multiplication, but on the skill of learning itself. The researchers are not so willing to dismiss entirely the use of computer games to teach such things as vocabulary or spelling, or to consider all drill-and-practice games examples of poor pedagogy. 
Lacasa, Mendez, and Martinez (2008) suggest that one change should be made to traditional videogames is that instead of rewarding good performance by making the game easier, the game should adapt to the player's skill level, ensuring that poorer players are not shut out by too-great difficulty, and better players do not find the later levels too easy, due to rewards gained for more skillful play. At present, neither of the computer games considered in this study is capable of adaptive difficulty, but the concept is still worth mentioning, perhaps as a future design goal.

Gee (2005) outlines thirteen principles of good learning design within four larger categories. He claims that these principles are common in successful commercial computer game design, and are applicable to education in general, including, but not limited to educational computer gaming. Good computer gaming, according to Gee, is participatory, customizable, allows risks to be taken, guide users' early experiences so they will learn the skills needed to be successful later, has variable difficulty levels to slightly frustrate, but not stymie, the player, and encourage systemic thinking, problem solving, and understanding. These can all be adapted into traditional education, whether computer games are used or not. Kiili's (2004) theoretical model, though couched in more technical terms of flow, cognitive load, and experiential learning, is quite similar to Gee's, focusing on problem solving, immersion, progressive difficulty, and challenge. Both theoretical models tend to follow Papert's (1998) suggestion that simulations are superior to drill-and-practice video games. However, the realities of teaching and learning still require basic factual information to be learned, and provide situations where shorter, simpler, drill-and-practice games may be needed. A teacher who has computer stations at which students spend 15-30 minutes per session may find that students barely have time to become engaged with a detailed simu- lation, while in the same amount of time, they could play through several rounds of a shorter, simpler, drill-and-practice game.

\subsection{Types of Educational Video Games}

Computer games, as used in education, can be divided into two main areas. They are either the repurposing of commercial off-the-shelf computer games for educational purposes, or computer games specifically created for education. Research on educational computer games generally focuses on one of the aforementioned types, either repurposed commercial video games or dedicated educational video games.

\subsubsection{Commercial Off-the-Shelf Games in}

Education. There are three major reasons to recommend the use of commercial off-the-shelf computer games as educational tools. First, they have usefulness in spurring on class discussion by allowing students to immerse into a new environment. They also have an ability to create schema for understanding academic concepts. Finally, such games can increase problem-solving skills in general.

With regard to virtual experiences and new environments, Lacasa, Mendez, and Martinez (2008) conducted a study in which classrooms in Spain used The Sims, a commercial off-theshelf video game, in a writing unit about family structure. With guidance from teachers, students were able to explore different types of families through the virtual world of The Sims, and use those experiences as the basis for their writing. The experience was successful, in large part because it allowed the students to understand family situations beyond their own via virtual experiences.

Abrams (2009) compared three case studies conducted in New Jersey Schools to explore the ways in which computer games helped under-performing students to form schema that helped them in their school envi- 
ronment. Through interviews, shadowing, and observations, Abrams found that students developed schema from what they saw in commercial video games played outside of school hours. One participant, for example, learned the word 'brackish' from the environment 'Brackish Lake' in the game Gears of War. Another understood Othello's origins because he had encountered the Moors in the game Total War, and a third had played through the Normandy Invasion in the first person shooter Medal of Honor, giving him a perspective on the history of World War II that most of his fellow students lacked.

Blumberg, Rosenthal, and Randall's (2007) observations of ten frequent and ten infrequent adult video gamers in New York City supported Abrams' findings. Their participants played Sonic the Hedgehog 2 for Game Gear for twenty minutes and were encouraged to comment aloud using the Think Aloud method, especially when they reached an impasse in the video game and had to alter or invent new strategies to move past the gridlock. They found that frequent gamers had more insight and strategy comments to share, and had developed a personal schema for problem-solving within the context of video game challenges.

\subsubsection{Video Games Created Specifically for}

Education. In general, using computer games in lieu of traditional instructional methods has not been found to be significantly correlated with increases or decreases in achievement, but has been correlated with greater engagement and time on task in Chilean first and second grade students (Rosas et al, 2002), American fourth and fifth graders (Ke, 2008), and engineering graduate students (Ebner \& Holzinger, 2007). Chang and Chen (2009), however, found that third graders from Taiwan experienced increases in both content learning and engagement when using video game-based learning as opposed to text-based computer aided instruction. Regardless of whether or not instruction- al gains are significant, gains in engagement and attention, with their related reduction in disciplinary issues, are worth pursuing. With the establishment of educational video games' value, discovering which types of video games provide the best results is important.

Although Papert (1998) holds that deceiving students as to whether or not they are learning implicitly is dishonest and counterproductive, learning is still a topic of interest. Ciavarro, Dobson, and Goodman (2008) undertook a study of 59 ten to fourteen year olds who played a video game called Alert Hockey, which had a karma system designed to secretly reinforce either safe or aggressive play. They had originally planned to include older teenagers in the experiment, but those older than fourteen years generally did not find the game engaging, possibly because of its obsolete graphics, and so they did not want to play the game. Participants were expected to play Alert Hockey to win, not with any particular learning goal in mind. There were two experimental groups and one control group. One experimental group played a version of Alert Hockey which implicitly taught safer hockey playing by penalizing the kinds of negligent and aggressive play that increases the risk of concussion and other injury among hockey players. The other experimental group played an opposite version of Alert Hockey that rewarded aggressive and negligent behaviors. The control group played a version that neither rewarded nor penalized such behaviors. Ciavarro, Dobson, and Goodman found that the pro-safety experimental group played the game more safely as the experiment progressed. The proaggression experimental group played more aggressively overall, but did not change significantly as the experiment progressed. The control group had no significant change, thus lending support to the idea that implicit learning can be an effective strategy, if the game is engaging to its target audience. 


\subsection{Computer Games for Language Learning}

deHaan (2005) undertook a case study of one Japanese adult male student who played Jiikoo Pawafuru Puro Yakkyu, a commercial Japanese-language baseball game for the Nintendo 64 game system. deHaan found three major factors in video games that aided in language learning: (1) repetition, which allows players to learn things in context, repeat actions, and extrapolate/bootstrap understanding of the language from the context of the game play and the familiarity of the general interface and menu systems, assuming they were already familiar with video games in their own language; (2) control, which allows players to repeat actions, pause the game to consider, and generally control the flow of what was going on in a game in ways they could not when using video or audio learning aids; and (3) the presentation of text and audio together. This combination had been shown to be effective in young students learning to write in their first language, and may hold positive effects for students learning a second language. Over time, the one participant improved his Japanese listening score, understood more, found easier to play the game, and came to focus less on partially-English "loan word" phrases and more on purely Japanese ones (deHaan, 2005).

Piirainen-Marsh and Tainio (2009) undertook similar case study of students learning a second language through playing a commercial video game produced in that language took place. They observed two Finnish boys playing the English-language localized version of the fantasy role-playing game, Final Fantasy X, with the goal of discovering how their collaborative play unfolded when encountered with a different language. The participants tended to repeat the lines said in the cut scenes, which were both spoken and subtitled, and read written information such as menu options aloud, as a way to understand through seeing, hearing, reading, and speaking the language. The boys worked together, conversing in Finnish, but also bringing English words and phrases from the game into their discussion.

With such success in using computer games to help in the acquisition of a second language, the researchers of this study intended to examine two types of short, simple computer games. By permitting participants to play with the games as they practice some basic phrases of Spanish greetings, the researchers wanted to ascertain whether one type of game was more effective than another.

\section{Problem Statement}

The purpose of this study was to determine if there were any meaningful differences in satisfaction, engagement, and Spanish language content learning among college-educated adults playing two different computer games designed specifically for teaching Spanish language content. The researchers hypothesized participants who played the computer game called Shoot 'Em, which was based on the classic arcade game of Space Invaders, would report a greater degree of satisfaction, engagement, and improvement in test scores than those playing Match 'Em, which was a game based on the traditional matching card game Memory. The researchers also hypothesized that participants playing both video games, on average, would score higher on the post-tests than pre-tests after practicing what had been learned. Finally, the researchers propose that participants playing Shoot ' $\mathrm{Em}$ will attain a greater increase in test scores between their pretests and post tests than those playing Match 'Em.

Computer games are popular, ubiquitous, and many are available for free, including Buensoft Spanish, which includes both computer games used in this study. With that in mind, the question of computer games' educational potential in language learning is difficult to ignore. Little research is available on the use 
of computer games in language learning, and that which is available is largely qualitative in nature, focusing on one or a few individuals playing a commercial video game over a long period of time. While these studies can provide great insight, they neither address the use of dedicated educational computer games nor provide statistical analysis. Nor does the existing research compare different video games to each other, leaving an important question unaddressed. Quantifiable instruments and general descriptive information were used to provide a foundation and examination of the procedures for performing larger research studies. Further, the descriptive findings provided insight into possible variables for further research that the researchers did not anticipate.

\section{Methods}

\subsection{Participants}

Participants for this study included four college students who attended the university. The small number of participants rendered a statistical approach for this study impossible, so the participants' opinions, demographic information, test scores, and comments served to illustrate the changes that took place. To this end, the researchers took an approach more typically used in qualitative research by examining each participant individually, and then looking for themes that appear in the data that is present and coding the written comments on the surveys via content analysis and observations.

The participants were either current university students or recent graduates, and all were over twenty-one years of age. Three were female, and one, the current graduate student, was male. All had some previous training in the Spanish language, having taken courses in high school, but none were conversant or fluent. All four participants knew the primary researcher, but the recruiting process was not meant to create a sample of convenience. Instead, the primary researcher addressed several classes full of current university students, asking for participation, but only those who knew him personally responded. Thus, this may be more correctly called a failure in the publicizing and recruitment process than an intentional sample of convenience.

Participants were given random numbers used for identification and to designate which educational video game each participant would play (see Table 1). Participants with even numbers played Shoot 'Em, while odd numbers played Match 'Em.

Table 1. Participants by Classification, Gender, and Ethnicity

\begin{tabular}{llll}
\hline Participant Characteristics & Classification & Gender & Ethnicity \\
\hline Participant 10 & Undergraduate & Female & African-American \\
Participant 16 & $\begin{array}{l}\text { Recent Master's } \\
\text { Graduate }\end{array}$ & Female & White \\
Participant 25 & Graduate Student & Male & White \\
Participant 29 & Undergraduate & Female & African-American \\
\hline
\end{tabular}




\subsection{Design and Instruments}

The researchers undertook a mixed-methods study approach in order to gain correlative data detecting any existing differences between different types of educational computer games, specifically concerning both learning achievement and satisfaction and engagement, which were measured by a questionnaire. The questionnaire included an open-ended question to encourage participants to share their thoughts and opinions on the computer game they played, the Buensoft program, and upon the research study itself.

Quantitative research would be an appropriate method to use when looking to detect differences and correlations, especially when a large sample size is expected. A mixedmethods approach was, however, the most appropriate approach because the researchers were not only interested in the correlations and differences that could be established through quantitative methods, but also in any emergent themes or trends that might be found in the participants' answers to the qualitative, open-ended survey item.

At different points in the study, participants completed pre-tests, post-tests, and satisfaction/ engagement questionnaires. For the pre- and post-tests, vocabulary phrases were taken from a pre-existing Buensoft Spanish lesson called Basic Spanish Greetings. The pre- and posttests were designed as multiple-choice tests, using each of the vocabulary phrases twice. The majority of the items were written to be surface-recall only, either giving the Spanish phrase and asking for the English translation, or giving the English phrase and asking the participant to select the Spanish translation. A few items, however, were written to require a degree of application and critical thought. In order to be certain that both tests were assessing the same content while simultaneously reducing the practice effect, the pre-test and post-test used the same questions, given in a different order, with the order of the responses changed as well.

The satisfaction questionnaire was written to judge not only satisfaction, but also engagement, using objective items on a Likert scale and an open-response question designed to generate qualitative data to enhance the researcher's understanding of the participants' experiences. Demographic information was gathered in hopes of using the information to analyze sub-groups, given sufficient numbers of participants. With only four participants, the statistical approach was no longer tenable, and so each individual's responses, comments, and test scores were examined individually, through more qualitative and descriptive methods. In fact, the reporting of findings are more like a case study type of approach that discusses the changes in the instruments used, how each participant viewed the study itself, and the researchers' observations during the course of the sessions.

\subsection{The Educational Video Games}

The two educational computer games, Match 'Em and Shoot 'Em, were chosen for several reasons. First, they were both a part of the same software suite, Buensoft Spanish 2004, which meant they would by default share the same vocabulary lists. Buensoft Spanish 2004 was chosen because its free version had a wide range of vocabulary, reinforcement activities, and learning games available, and because a new version was scheduled to be released in 2011, allowing further research in using the revised, up-to-date program.

The two games, Match' Em and Shoot 'Em, were chosen from the various programs available because of their differences. Though they were both drill-and-practice games, Match 'Em is memory-based and demands nothing of the 
player's reflexes, while Shoot 'Em is a fastpaced action game. Match 'Em puts the player under minimal stress, as there was no way to lose, and the player was competing against his or her own best times, while Shoot 'Em was difficult, stressful, and required the player's total concentration. Match 'Em also provided continual audio feedback and reinforcement of the English and Spanish phrases, while Shoot 'Em dedicated most of its audio to sound effects, reading the Spanish phrase only if the player finishes the level.

Although some may dismiss drill-andpractice games in favor of more sophisticated simulations, those types may not always be practical. In many classroom situations, there is simply not enough time for a player to get deeply immersed in a simulation. The kinds of games that involve steep learning curves, fantasy, lateral thinking, identification with characters, and applications of real-world skills typically take hours, if not tens of hours. That length and complexity is part of the appeal of such simulations; being too short is as much a fault as being too easy. In classroom situations or any time that the player wants to learn through gaming and does not have much time to devote to it, simpler games are called for. To that end, simpler, action-based, drill-and-practice games may still have a legitimate place at the educational gaming table.

4.3.1. Match 'Em. Match ' $E m$ is a one-player, multimedia variation of the classic children's game known as Concentration, Pairs, or Memory, in which players try to match cards with the same value or picture, flipping them over in pairs. If the pairs match, the cards are removed. In multiplayer versions, the goal is to get the most pairs (Arneson, 2011). In this oneplayer version, the goal is to get the best time.

There are twenty cards shown on the screen, face-down, two for each phrase in the subject set. One card in each pair shows the
English phrase, and the other shows the Spanish phrase. When each card is flipped over, an audio recording of the Spanish phrase is read aloud. When the Spanish-language card is flipped, this audio recording serves to model correct pronunciation. When the English-language card is flipped, the Spanish audio serves to connect the English meaning with the Spanish phrase.

The elapsed time is shown in the upper right corner, and the cards, when flipped, show either the English or Spanish translation of a given phrase. If the cards match, they are removed. The player cannot lose the game, at least not within the thirty minutes of play time provided in this experiment, and is competing only against the clock to score the best possible time. After each game, the time is recorded and the game closes. The Buensoft interface stays open, however, and the player need only click Match 'Em to play again.

4.3.2. Shoot ' $\mathbf{E m}$. Shoot ' $E m$ is a variation on the classic arcade game of Space Invaders, in which the player controls the cannon that he or she can move from side to side using the left and right arrow keys. To fire at the objects on the screen, control or space keys are used. The player's cannon can take cover behind any of the five shields. The shields absorb any attack that hits them, whether originating from the player's cannon or the invaders, losing part of their structure in the process. The player's cannon can also shoot down enemy missiles, though not at a rapid enough rate to avoid the necessity of dodging. The player begins with three cannons, and can gain extras in the course of gameplay. A single shot from an enemy will destroy the cannon, but likewise, a single shot from the cannon will destroy any enemy in the game.

The total number of cannons is displayed in the upper right corner of the screen, including the current cannon in use. The player's score 
is displayed in the upper left-hand corner. The English translation of the word or phrase the player is attempting to spell out appears at the center of the bottom of the screen. The player's progress in completing the phrase is shown in the top center of the screen, showing the letters already shot, in the correct order, and spelling out the phrase as the player completes it.

The goal of Shoot 'Em is to spell a Spanish word or phrase by shooting at letters in the correct order. Letters shot out of order do not disappear, though they usually move to the side slightly. Asterisks act as generic invaders firing at the player's cannon. Although they do not have to be shot in order to complete the level, shooting them is worthwhile as they give either bonus points or extra cannons. If the player completes the word or phrase, an audio recording of its pronunciation is played, and the next level is loaded. As in the original Space Invaders, the player can lose the game either by having all of his or her cannons destroyed or by letting the invaders reach the bottom of the screen. Shoot 'Em does not show the player the correct translation, nor does it play an audio version, unless the player completes the level.

\subsection{Procedures}

Participants were recruited from the university. Those with a significant prior knowledge of Spanish were discouraged from participating. Any student who indicated Spanish language fluency in the engagement questionnaire would be excluded after the fact. The primary researcher attended, and recruited from, several undergraduate classes. When that failed to produce an adequate number of participants, personal acquaintances of the researcher were solicited. The researcher's original intent was to study university undergraduates, because they were a group of people who commonly attempted to learn additional languages, and because their generally young age would allow a degree of generalization of the results to high school students, another group that frequently attempts to learn languages. Only two undergraduates responded, both of them older, nontraditional students, so the researcher was forced to expand the scope of the project to include all adults. Although the primary researcher teaches undergraduate classes, he was unable to recruit from those classes due to ethical concerns.

The research instruments were developed by the researchers themselves. The three research instruments included a pre-test composed of twenty multiple-choice questions, two for each of the ten vocabulary phrases; a post-test that used the same questions as the pre-test, but in a different order, and with the order of their responses similarly shuffled; and a satisfaction survey that included demographic items, questions concerning satisfaction with the educational video game played, and questions concerning engagement with the game.

The research sessions all took place on weekday evenings in the same computer lab. The total time took between fifty and sixty minutes for each session, and each participant participated only once. Participants were identified only with a randomly assigned identification number, thus making the participants' identities completely anonymous. Each research session went in the following order: an introduction of the researcher, a presentation of the informed consent forms, an introduction to the vocabulary list, distribution of the pre-test, thirty minutes of video game play, distribution of the post test, and the completion of the satisfaction survey. The pre-test followed immediately after the introduction, and the participants were given no more than 15 minutes to finish the pre-test. The participants immediately played their randomly assigned computer game for thirty minutes, after which the post-test and satisfaction surveys were immediately administered. As soon as the participants finished the post-test and survey, they were dismissed. 


\section{Findings}

\subsection{Data Analysis}

The researcher's original intent was to statistically analyze the pre-test and post-test results, using a mixed ANOVA design, to detect any differences in achievement between participants who played the two different games. Likewise, measures of engagement and satisfaction would be analyzed to detect any differences in achievement between participants who played the two different games. However, because the researchers were only able to recruit four participants, the aforementioned analysis methods were no longer practical. As such, each participant is looked at in detail, examining their test results, satisfaction, engagement, and comments concerning the games. In addition, researchers' observations of participants' behavior are addressed to help supplement the quantifiable instruments.

\subsection{Composite Satisfaction and Engagement Scores}

To create an overall Satisfaction score, the mean of the participant's answers to question 8, 'The software helped me learn the content,' question 9, 'The software was more enjoyable than traditional study methods,' question 10, 'I would choose to use this software again,' and question 14 'This was a good way to begin learning Spanish’ was calculated.

Creating an overall Engagement score was somewhat more complicated, as question 15, 'The layout of the graphic elements was distracting,' is on an opposite scale than the other questions, so that 5 is a 'strongly unfavorable' response and 1 is a 'strongly favorable' response. Thus, the initial step is to first change the Participant's answer to question 15, 'The layout of the graphic elements was distracting,' to a reversed statement, so that a 'Strongly Agree: 5' becomes a 'Strongly Disagree:
1,' an 'Agree: 4' becomes a 'Disagree: 2', a 'Neutral: 3' stays a 'Neutral: 3,' a 'Disagree: 2' becomes an 'Agree: 4,' and a 'Strongly Disagree: 1' becomes a 'Strongly Agree: 5.' The reversed rating for question 15 , 'The layout of the graphic elements is distracting,' is added to the participants' answers to question 7, 'The software increased my motivation to succeed,' question 11, 'The software was engaging,' question 12, 'The software forced me to think quickly,' question 13, 'The audio feedback was helpful,' and question 16, 'The color contrast in the game helped emphasize important information,' and the mean was calculated.

\subsection{Results}

The following descriptions document findings that resulted from the study. Each participant is described in a descriptive format that covers a comparison between the pre- and post-tests, his/her responses to the satisfaction survey, and general observations of behavior (see Table 2).

Table 2. Participants Pre- and Post-test Scores

\begin{tabular}{lcc}
\hline $\begin{array}{l}\text { Participant Test } \\
\text { Scores }\end{array}$ & $\begin{array}{c}\text { Pre-test } \\
\text { Score }\end{array}$ & $\begin{array}{c}\text { Post-test } \\
\text { Score }\end{array}$ \\
\hline Participant 10 & 13 & 18 \\
Participant 16 & 19 & 20 \\
Participant 25 & 19 & 18 \\
Participant 29 & 19 & 17 \\
\hline
\end{tabular}

5.3.1. Participant 10. Participant 10 had the lowest pre-test score of the four participants, scoring 13 out of 20 . The other three participants all scored 19 out of 20 on the pre-test, meaning that Participant 10 answered only two thirds as many questions correctly as the other participants. On the pre-test, Participant 10 answered questions $2,3,4,10,12,13$, and 16 incorrectly. These questions concerned the times of days of the various greetings: buenos dias, buenas tardes, and buenas noches, as well as the meaning of como esta usted. 
During the computer gaming portion of the session, Participant 10 played Shoot 'Em, the Space Invaders clone. After playing, her post-test score was 18 out of 20 , the median result among all participants, and the greatest increase in test score by far. On the posttest, Participant 10 missed questions 1 and 9. Question one concerned the timing of buenos dias, which she had missed on the pre-test, but she correctly answered all of the other questions concerning the timing of buenos dias, buenas tardes, and buenas noches. Question nine concerned the correct use of hasta luego and adios, but was one of the more difficult questions on the test.

Participant 10 arrived slightly early for the session, appeared to be very attentive during instruction, and seemed highly engaged during game play. After the session ended, she asked if it was possible to return to the lab and play the game again at a later date, in order to improve her Spanish language skills. This could account to her great improvement between the pre-test and post-test scores. Attitude and motivation are major factors toward learning.

Participant 10 reported a very high level of satisfaction and engagement with the software. She 'Strongly Agreed' with the statements, 'The software helped me learn the content,' 'The software was more enjoyable than traditional study methods,' 'I would choose to use this software again,' and 'The software forced me to think quickly.' She 'Agreed' with the following statements, 'The software increased my motivation to succeed,' 'The audio feedback was helpful,' and 'This was a good way to begin learning Spanish.' She was 'Neutral' regarding 'The software was engaging' and 'The color contrast in the game helped emphasize important information,' and she 'Disagreed' with the single negative statement that, 'The layout of the graphic elements was distracting.' Participant 10's mean Satisfaction was 4.75 out of a possible 5.0, the highest of all the participants, and her mean Engagement was 3.83 out of a possible 5.0, the second-highest of all participants. Her written comments were completely positive in that she explained:

I liked this experience. I always wanted to help improve my Spanish skills, but never could remember simple phrases. I love the fact that this is a game because I love games. The game Shoot 'Em makes you think quickly and makes you remember how the correct Spanish word is spelled. I would really recommend this software to help students learn Spanish.

5.3.2. Participant 16. Participant 16's pretest score was 19 out of 20 . She missed question 12 , a question concerning the timing of buenas tardes. She verbally complained that she found the wording of that question confusing and wrote a note to that effect under the question when it appeared again on the posttest. During the computer gaming portion of the session, Participant 16 also played Shoot 'Em, the Space Invaders clone. After playing, her post-test score was a perfect 20, the highest score possible, and the only perfect score among all participants.

Participants 16 and 10 were the only participants whose scores increased from pretest to post-test. However, Participant 16 did not share Participant 10's high opinion of the Shoot 'Em game. Participant 16 was visibly frustrated throughout the course of game play, and vocally expressed her frustration afterward, giving verbal feedback in addition to her written comments. She told the researcher that she would have given more written feedback, but "I got tired of writing." She also suggested that the post-test may be affected by the mental fatigue of playing a video game for thirty minutes directly beforehand. 
Participant 16 'Strongly agreed' that 'The layout of the graphic elements was distracting.' Because her computer was accidentally left muted during the gaming portion of the experiment, something neither she nor the researcher noticed until it was too late, she chose a 'Neutral' response to 'The audio feedback was helpful.' She 'Strongly disagreed' with every other proposition. Her mean Satisfaction Score was 1.00, and her mean Engagement score was 1.33, although her 'Neutral' response to the question about audio feedback most likely inflated her final score. Needless to say, Participant 16's Engagement and Satisfaction scores were the lowest of all the participants.

Participant 16 was quite critical of the game, both in her written response and in spoken comments. For instance, she stated that, "I hated everything about the Shoot 'Em game!!! It was not educational unless the student already knew the vocabulary, which in that case, what's the point. The presentation would have been much more effective if both the Eng. \& Span. Translations had been on the screen at the same time. The audio for that part was helpful." She also added another observation by saying the "The game was frustrating and was not actually teaching anything. The player already had to know the information. It was tedious and it never told you the correct answer. You could play 100 games \& never solve a puzzle \& walk away knowing nothing more than when you began. This could have easily been corrected by giving the correct answer when the player did not solve the puzzle." Participant 16 also exhibited verbally that the Shoot 'Em game did not teach vocabulary, but spelling, and the game would not be an appropriate teaching tool for a lesson concerning Spanish language meanings and usage, which is what the pre- and post-tests measured.

5.3.3. Participant 25. Participant 25 scored 19 out of 20 on the pre-test, missing only question 11 , a question about the correct use of adios and hasta luego. During the computer game portion of the study, Participant 25 played Match 'Em, a memory based card-flipping game. He then scored 18 out of 20 on the post-test, incorrectly answering question 8 , a question about the meaning of como esta usted and question 9 , the post-test counterpart to the question he answered incorrectly on the pretest.

Participant 25 arrived on-time for the session, and seemed relaxed and comfortable with the research setting. He appeared to be neither engrossed nor frustrated during the game, and did not give much additional information after the session, other than pleasantries and social conversation. Participant 25 reported moderate levels of satisfaction and engagement with the game software. He 'Strongly Agreed' with only one statement, 'The software forced me to think quickly.' He 'Agreed' with the following statements, 'The software was more enjoyable than traditional study methods,' 'I would choose to use this software again,' 'The software was engaging,' 'The audio feedback was helpful,' and 'This was a good way to begin learning Spanish.' He was 'Neutral' regarding 'The software increased my motivation to succeed,' 'The software helped me learn the content,' 'The color contrast in the game helped emphasize important information,' and 'The layout of the graphic elements was distracting.'

Participant 25's mean Satisfaction was 3.75 out of a possible 5.0, the second-lowest of all participants, and his mean Engagement was 3.67 out of a possible 5.0, also the second-lowest of all participants. A 'Neutral' response carries a numerical value of 3 , so both Participant 25's Satisfaction and Engagement are just slightly above the 'Neutral' level. His comments reflect his ambivalence toward the game stating that "30 minutes may be too long. I found myself 'zoning out.' I found myself only really thinking about what I was looking at every now and then. I wasn't really focused on the content or the words, just matching." 
5.3.4. Participant 29. Participant 29 scored 19 out of 20 on the pre-test, as did Participants 16 and 25. Participant 29 incorrectly answered question 15 on the pre-test, and its counterpart, question 13 on the post-test, but she did so in a way that revealed a weakness in the question, which states 'You Tell Maria your name, and she responds with:' The correct, expected answer is 'Me llamo Maria,' or, translated, 'My name is Maria.' Participant 29 selected 'Mucho Gusto Maria.' 'Mucho gusto,' or 'it's good to meet you,' as a reasonable response when being introduced to somebody, so it was impossible to tell whether Participant 29 had been actually incorrect, or whether she simply saw the situation differently than the test-writer did. In future iterations of this research, that test item will have to be revised, and the 'mucho gusto' distracter replaced by a different selection.

During the computer gaming portion of the session, Participant 29 played Match 'Em, the memory-based card-flipping game. After playing, Participant 29 obtained the lowest score of all the post tests: 17 out of 20 . In addition to the aforementioned question 13, she also incorrectly answered questions 7 and 9, which concerned appropriate use of adios and hasta luego, questions she had answered correctly on the pretest.

Like Participant 10, Participant 29 arrived slightly early to the session, was attentive during the session, and appeared to be engaged during game play. Like Participant 10, she asked about further opportunities to make use of the Buensoft program, thus indicating her motivation to continue learning. Participant 29 reported high levels of satisfaction and engagement with the game software. She 'Strongly Agreed' with the statements, 'The software helped me learn the content,' 'The software forced me to think quickly, 'The audio feedback was helpful,' and 'This was a good way to begin learning Spanish.' She 'Agreed' with the following statements, 'The software in- creased my motivation to succeed,' 'The software was more enjoyable than traditional study methods,' 'I would choose to use this software again,' and 'The software was engaging' She was 'Neutral' regarding 'The color contrast in the game helped emphasize important information,' and she 'Disagreed' with the single negative statement that 'The layout of the graphic elements was distracting.' Participant 29's mean Satisfaction was 4.5 out of a possible 5.0, the second-highest of all participants, and her mean Engagement was 4.17 out of a possible 5.0 , the highest of all participants. She commented, "I found the game to be an easy way of learning to speak Spanish. It would probably be effective in learning in other areas of study. I enjoyed it."

\section{Conclusions and Discussion}

The participants' generally positive responses to the experience of playing Shoot 'Em and Match 'Em are consistent with the high levels of engagement found by previous studies such as Rosas, et al (2002), Ke (2008), Ebner and Holzinger (2007), and Chang and Chen (2009). These studies discovered that students, regardless of age or ethnicity, tended to prefer video-based games when learning new content compared to traditional modes such as written text. Ultimately, there was no consensus or universal agreement as to which of the two games provided the better learning experience. Two participants played Shoot 'Em, and one hated the game while the other participant loved the game. Two participants played Match 'Em with one enjoying the game, and the other found his mind wandering. As far as the first hypothesis is concerned in that those participants who played Shoot 'Em would experience greater engagement, had mixed results, and thus, no conclusion could be drawn. The two participants were divided as to whether the Shoot 'Em game was engaging, and compared to Match 'Em, the results were the same. The 
second hypothesis in that the participants who played both games would experience, on average, increased test scores between pre-test and post-test was not supported by the study; both participants who played Match 'Em had post-test scores that were lower than their pretest scores. The results of the study, however limited, supported the third hypothesis, that those participants playing Shoot 'Em would attain greater gains in their test scores, as both participants who played Shoot 'Em evidenced increases in their post-test scores over their pre-test scores, while neither participant who played Match 'Em did so.

Although a sample size of four does not lend itself to sure conclusions, some patterns arose. The two undergraduates, both of whom were African-American, had more favorable opinions of their respective computer games than the two graduates, both of whom were white. Both participants who played Match 'Em had post-test scores that were lower than their pretest scores, while both participants who played Shoot 'Em, including the one who so vehemently hated it, had post-test scores that were higher than their pretest scores. However, with the given small sample size, knowing whether or not these trends are valid or simply arose by chance alone from a pool of four participants is impossible to determine. But, these trends could lend to further studies in addressing demographic characteristics of computer game players and how these variables would affect the reception, motivation, learning curve, and opinions concerning educational computer games to learn a second language.

The results of this study imply that, in the realm of simple, drill-and-practice video games, the most effective games are difficult, even frustrating, and involve a certain degree of action, fast-paced decision making, and handeye coordination, and this is true regardless of whether the participant liked the game or not. In a classroom setting, a teacher can feel com- fortable allowing and encouraging students to play action arcade style computer games with educational content, even if they do not seem, at first glance, to reinforce the material as thoroughly as more relaxing, slower-paced games. Apparently, the frustration, and adrenaline of fast-paced games like Shoot ' $E m$ help the player to learn more than the continuous repetition of slower-paced games like Match 'Em.

The researchers' failure to recruit sufficient participants means that the study must be repeated in order to answer its research questions and test any research hypotheses. Leaving aside the recruitment problem, the pilot study uncovered several areas that could be improved prior to the project's second iteration. First, the vocabulary list chosen was perhaps too easy in that three out of the four participants scored 19 out of 20 , or $95 \%$, on the pre-test, and both Participants 16 and 25 commented verbally that they knew the words and phrases already. When running the study a second time, a more obscure set of vocabulary words should be chosen. Fortunately, even the free version of Buensoft has several vocabulary lists available, and this change would merely involve changing the pre-test and post-tests, not the video games.

Second, the pre-test was given after the introduction to the Spanish terms, and as such, did not show how much the participants knew prior to the flash card instruction. In future research, a pre-pretest may be in order. Finally, the pre-test and post-test measured both direct recall and application, but not spelling. Because Shoot 'Em is very spelling-focused, adding spelling questions may allow a greater degree of understanding of Shoot 'Em's effectiveness. In future research, analyzing each section separately, using a MANOVA, may be useful assuming sufficient participants can be recruited. Possibly, some of the test items were confusing and need to be rewritten. As Participant 16 suggested verbally, taking the post-test immediately after thirty consecutive minutes of 
video gaming may prove draining. To that end, a short rest period might be necessary between playing the computer game and taking the posttest, in order to allow the participants' eyes and minds to recover, so that fatigue does not affect post-test results.

Other suggestions for future research would include examining completely different types of computer games. Instead of using two forms of drill-and-skills games, exploring whether simulations or tutorials are more effective than drill-and-skills could be performed. In addition, one may benefit through an examination of whether different subject matter may benefit from a certain type of game is probable. For instance, tutorials are said to be used more to teach knowledge that is new or not previously covered, as opposed to drill-and-skills primarily used to teach knowledge that has been taught before and to serve as practice (O'Bannon \& Puckett, 2010). Given this postulation, experimenting with different types of games to teach various subject areas like science, math, English, history, etc. may prove most informative.

\section{References}

Abrams, S. (2009). A gaming frame of mind: Digital contexts and academic implications. Educational Media International, 46(4), 335347.

Arneson, E. (2011). Concentration/Memory - Card game rules. About.com. Retrieved May 5, 2011 from http://board-games. about.com/od/cardgames/a/concentration. htm

Blumberg, F., Rosenthal, S., \& Randall, J. (2007). Impasse-driven learning in the context of video games. Computers in Human Behavior, 24, 1530-1541.

Bourgonjon, J., Valcke, M., Soetaert, R., \& Schellens, T. (2009). Students' perceptions about the use of video games in the classroom. Computers \& Education, 54, 11451156.

Chang, T., \& Chen, W. (2009). Effects of computer-based video games on children: An experimental study. Educational Technology \& Society, 12(2), 1-10.

Ciavarro, C., Dobson, M., \& Goodman, D. (2008). Implicit learning as a design strategy for learning games: Alert hockey. Computers in Human Behavior, 24, 2862-2872.

deHaan, J. (2005). Acquisition of Japanese as a foreign language through a baseball video game. Foreign Language Annals, 38(2), 278-282.

Ebner, M., \& Holzinger, A. (2007). Successful implementation of user-centered gamebased learning in higher education: An example from civil engineering. Computers \& Education, 49, 873-890.

Entertainment Software Association. (2010). Essential facts about the computer and video game industry. Retrieved May 6, 2011 from http://www.theesa.com/facts/pdfs/ ESA_Essential_Facts_2010.PDF

Gee, J. (2005). Learning by design: Good video games as learning machines. E-Learning, 2(1), 1-12.

Ke, F. (2008). A case study of computer gaming for math: Engaged learning from gameplay? Computers \& Education, 51, 16091620.

Kebritchi, M., \& Hirumi, A. (2008). Examining the pedagogical foundations of modern educational computer games. Computers \& Education, 51, 1729-1743.

Kiili, K. (2004). Digital game-based learning: Toward an experiential gaming model. Internet and Higher Education, 8, 13-24.

Lacasa, P., Mendez, L., \& Martinez, R. (2008). Bringing commercial games into the classroom. Computers and Composition, 25, 341-358.

O’Bannon, B., \& Puckett, K. (2010). Preparing to Use Technology: A Practical Guide 
to Curriculum Integration (2nd ed.). Boston, MA: Pearson Education, Inc

Papert, S. (1998). Does easy do it? Game Developer, 88. Retrieved March 31, 2011 from http:/www.papert.org/articles/Doeseasy-doit.html

Piirainen-Marsh, A., \& Tainio, L. (2009). Collaborative game-play as a site for participation and situated learning of a second language. Scandinavian Journal of Educational Research, 53(2), 167-183.

Prensky, M. (2005). Engage me or enrage me. Educause Review. September/October 2005, 60-64.

Rosas, R., Nussbaum, M., Cumsille, P., Marianov, V., Correa, M., \& Flores, P., et al (2002). Beyond nintendo: Design and assessment of educational video games for first and second grade students. Computers \& Education, 40, 71-94.

\section{Contact the Authors}

Timothy Dedeaux, MS.

The University of Southern Mississippi

Email: timothy.dedeaux@eagles.usm.edu

Taralynn Hartsell, Ph.D.

The University of Southern Mississippi

Email: taralynn.hartsell@usm.edu 